\title{
3D ФОТОГРАММЕТРІЯ В АРХІТЕКТУРІ, МІСТОБУДУВАННІ ТА ЗБЕРЕЖЕННІ КУЛЬТУРНОЇ СПАДЩИНИ
}

\section{D PHOTOGRAMMETRY IN ARCHITECTURE, URBAN PLANNING AND PRESERVATION OF CULTURAL HERITAGE}

\author{
Волошин В.У., к.т.н., доц., Мельник О.В., к.т.н., доц., \\ Вакулюк Л.А., ст.викл., Рудик О.В., ст.викл. (Волинський \\ національний університет імені Лесі Українки)
}

\section{Voloshyn V.U., PhD in Engineering, associate professor, Melnyk O.V.,} $\mathrm{PhD}$ in Engineering, associate professor, Vakuliuk L.A., Senior Lecturer, Rudyk O.V., Senior Lecturer (Lesya Ukrainka Volyn National University)

Наземна фотограмметрія є доступним методом иифрового тривимірного моделювання в архітектурі, містобудуванні археології, тощо $i$ може бути виконана за допомогою недорогого споживчого обладнання. У всьому світі існує багато недокументованих будівель, зокрема в країнах, що розвиваються, які могли б отримати користь від 3D-моделювання для поновлення документації, перепроектування або реставрації. В статті описано методику тривимірної реконструкиії на прикладі пам'ятника погруддя Лесі Українки в м. Луцьку.

Ground-based photogrammetry is an affordable method of digital threedimensional modeling and can be performed using inexpensive consumer equipment. There are many undocumented buildings around the world, particularly in developing countries, that could benefit from $3 D$ modeling for documentation, redesign, or restoration. Areas with buildings that could be destroyed by a natural disaster or war are especially beneficial.

Compared to laser scanning, terrestrial photogrammetry is cheaper and more portable. At a minimum it requires a consumer-grade digital camera, a computer and some free software. This is widely attainable, even with low-cost equipment. Results may be strengthened by higher quality camera, proprietary software and possibly the addition of control points, which would require a total station. Though more expensive, this still costs less than laser scanning, and would ertainly expand the global availability of digital building modelling if adequate.

The process of obtaining a three-dimensional model using photogrammetry can be divided into the following stages: data collection; pre-treatment; image orientation; measurement and analysis.

The application of technology and methods of processing the obtained digital images was performed in Agisoft Metashape 1.76 software on the example of the 
monument by sculptor Galina Kalchenko - bust of Lesya Ukrainka, installed in front of building "B" of Lesya Ukrainka Volyn National University on Vynnychenko Street, 30 which was established in 1986 in honor of the 115th anniversary of the writer's birth.

Based on the three-dimensional triangulation frame model and stereo image pairs, a realistic textural model of the object is formed at the final stage. Despite the fact that modern methods of photogrammetry allow to solve most problems, including the use of widespread budget cameras, its implementation in real production remains scanty.

The results of photogrammetric three-dimensional reconstruction of objects can serve as a basis for further processing in CAD and BIM, significantly saving time for previous research.

Ключові слова: фотограмметрія коротких відстаней, иифрова камера, контрольні точки, тривимірна реконструкиія, тривимірна модель

Keywords: short-distance photogrammetry, digital camera, control points, threedimensional reconstruction, three-dimensional model

Вступ. Розвиток цифрових технологій та їх використання у різних сферах розвитку суспільства змінив підходи до багатьох галузей науки та освіти, зокрема, і до сфер будівництва, архітектури, які почали набувати нові функції та властивості, що дозволило перейти на якісно новий рівень опису, зберігання та обробки матеріалів дослідження. Впровадження сучасних геодезичних методів вимірювання просторового положення разом із цифровою фотозйомкою значно покращило практику прикладних досліджень. Методи 3D фотограмметрії дозволяють здійснювати збір даних прикладних досліджень більш оперативно та повно.

Тривимірна фіксація об'єктів має низку переваг перед традиційними методами документування, оскільки дає можливість створювати моделі, що повністю зберігають просторові характеристики досліджуваних об'єктів. Тривимірна модель дозволяє досліднику детально вивчати об'єкт 3 усіх кутів і ракурсів, навіть якщо він ніколи не бачив його на власні очі. Крім того, сучасне прикладне програмне забезпечення, що оперує тривимірними цифровими моделями об'єктів, дозволяє проводити просторовий та статистичний аналіз об'єкту дослідження.

Розвиток фотограмметрії в значній мірі визначається прогресом обладнання, обчислювальної техніки і суміжних геоінформаційних технологій. Особливості і проблеми, які виникають при використанні цифрової техніки 3 метою фотограмметричної зйомки, $є$ актуальним питанням на сучасному етапі розвитку наземної фотограмметрії, яка безперечно стає цифровою. 
Аналіз останніх досліджень. Багато авторів досліджували різні методи недорогого 3D-документування культурної спадщини на основі зображень [1,2]. В роботі [3] було протестовано недорогий підхід до реконструкції археологічних об'єктів за допомогою Agisoft Photoscan. Було отримано високоточні результати, хоча наголошувалося, що технічні знання та навички важливі. В дослідженні [4] оцінили практичні можливості та переваги недорогого моделювання на основі зображень для збереження спадщини в Непалі після руйнівного землетрусу 2015 року. Автори [4] дійшли висновку, що це має велике значення, враховуючи значну кількість об'єктів культурної спадщини, які перебувають у небезпеці по всьому світу, документування яких неможливо вирішити без БПЛА або засобів наземної фотограмметрії. $Є$ також численні дослідження щодо моделювання на основі зображень для складних сучасних будівель. Наземну фотограмметрію порівнювали 3 лазерним скануванням для точного моделювання архітектурних об'єктів автори роботи [5]. Попри велику кількість проведених досліджень, актуальність i новизна застосування методів фотограмметрії в різноманітних галузях залишається на високому рівні.

Постановка завдання. Сучасне інформаційно-комп'ютерне моделювання та проектування для вирішення питань досліджень різних об'єктів, від об'єктів археології до об'єктів культурної спадщини, від окремих фрагментів фасадів будівель до комплексної тривимірної реконструкції будівель у містобудуванні та архітектурі, потребує оперативного одержання високоточних даних про поверхню об'єкту дослідження.

Для тривимірної фіксації об’єктів застосовуються дві різні технології - лазерне сканування та наземна фотограмметрія. В порівнянні з наземною фотограмметрією лазерне сканування забезпечує кращу точність, проте вимагає застосування високовартісного обладнання та спеціального програмного забезпечення. Крім того, застосування лазерних сканерів у польових умовах потребує спеціальних навичок та знань. 3D фотограмметрія дозволяе отримати придатні для подальшого використання тривимірні моделі лише за допомогою цифрової камери та ПК зі спеціалізованим програмним забезпеченням.

Метою даної роботи є апробація методики 3D фотограмметрії для побудови тривимірних моделей об`єктів на конкретному матеріалі. 
Виклад основного матеріалу. Фотограмметрія вивчає явища, форми й положення різних предметів у просторі, об'єкти та їх розміри шляхом вимірювань їх фотографічних зображень [6]. Предметом фотограмметрії $\epsilon$ вивчення властивостей фотозображення, методів його отримання i вимірювання, розробка приладів для вимірювання i перетворення фотозображень.

Найбільш широке застосування фотограмметрія має в геодезії i топографії при картографуванні земної поверхні, а також у космічних дослідженнях. В архітектурі фотограмметрія застосовується 3 метою визначення форми, розмірів, просторового положення i якісних характеристик різних архітектурних об'єктів для вивчення і реставрації будівель, особливо тих, які мають історичне значення. Об'єкти досліджуються щонайменше за двома знімками об'єкту з різних точок простору (стереопари) безконтактним визначення координат точок об'єкта і на основі відтворення моделі об'єкта. Використання комп'ютера та програмних засобів для ефективної обробки фотограмметричних матеріалів $\epsilon$ їх важливою властивістю.

Розвиток обчислювальної техніки надав потужний імпульс розвитку методів фотограмметрії і зробив можливим автоматизовану обробку зображень за допомогою персонального комп'ютера, що збільшило іiі доступність та суттєво розширило межі технології.

На даний момент поєднання цифрової фотозйомки та спеціалізованого програмного забезпечення дозволяє створювати деталізовані тривимірні моделі як окремих об'єктів (залишків споруд, поховань тощо), і цілих ділянок місцевості [7]. Таким чином, незважаючи на те, що сам термін «фотограмметрія» має досить широке значення, ми розумітимемо під ним метод побудови тривимірних моделей об'єктів за допомогою комп'ютерної обробки цифрових знімків.

Процес отримання тривимірної моделі за допомогою фотограмметрії можна розділити на наступні етапи (рис. 1):

- Збір даних;

- Попередня обробка;

- Орієнтування знімків;

- Вимірювання та аналіз. 


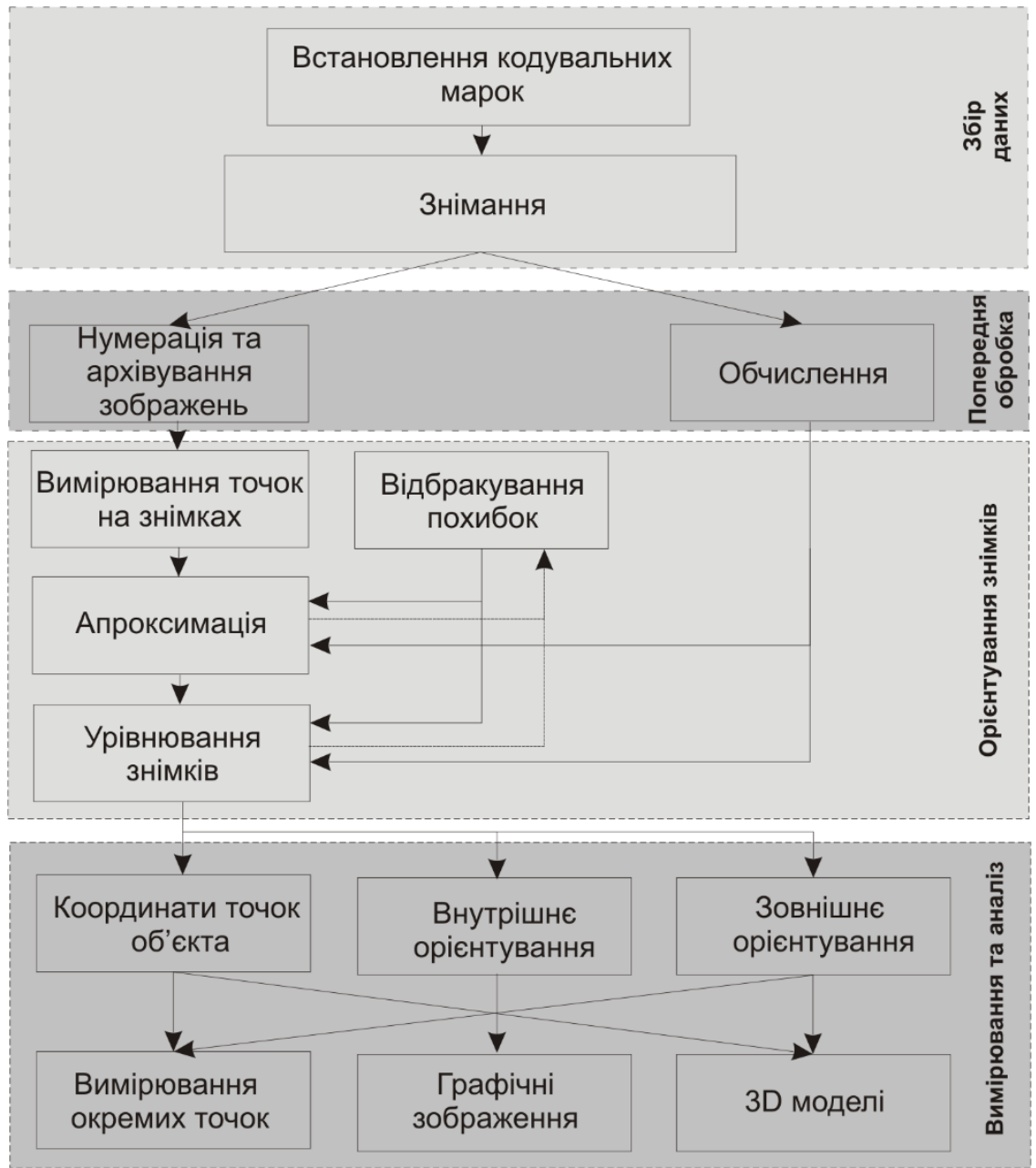

Рис. 1. Процедура отримання та аналізу зображень

На попередньому етапі здійснюється вибір спеціальних (контрольних) марок за допомогою яких визначається зовнішня система координат та визначається взаємне положення точок об'єкта на зображеннях.

Такі марки наносяться (приклеюються) на об'єкт зйомки в місця, де необхідно виконати вимірювання координат. При цьому марки повинно бути видно як мінімум 3 двох точок зйомки. Після нанесення мішеней та маркерів, що визначають контрольні точки, проводиться зйомка об'єкта 3 
різних сторін та під різними кутами. Приклад контрольних марок наведено на рис. 2.

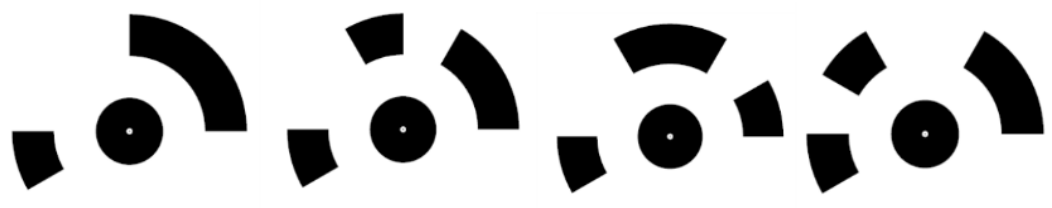

Рис. 2 Кодувальні марки

На етапі зйомки здійснюється кілька серій фотографій, що ніби «обплітають» об'єкт і покривають його поверхню з усіх ракурсів (рис. 1). Кожна наступна фотографія серії повинна перетинатись (накладатись) 3 попередньою як мінімум на $30 \%$, що дозволить програмному забезпеченню об'єднати знімки. Оскільки при розрахунку геометрії цифрової моделі використовується метод тріангуляції, тому кожна точка об'єкта повинна бути як мінімум на трьох фото. Чим більше таких точок буде знайдено, тим точніше буде цифрова модель.

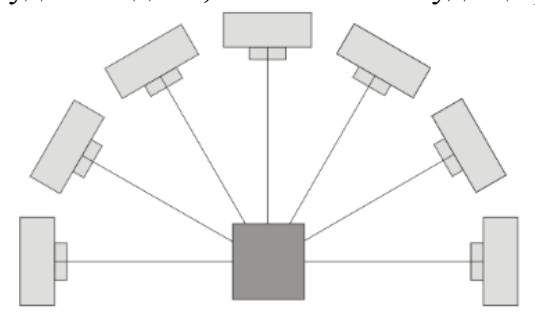

a)

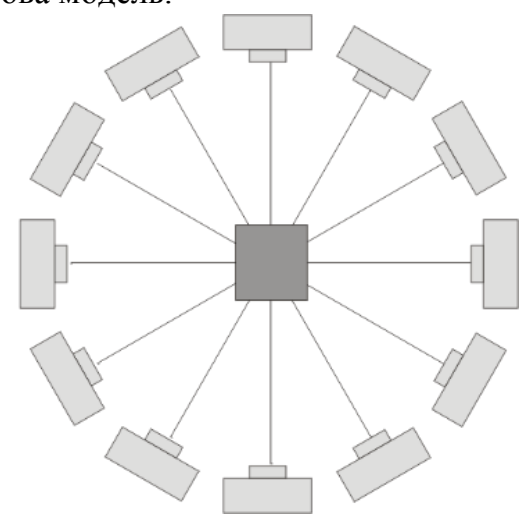

б)

Рис.3. Позиції цифрової камери під час зйомки об'єкта:

а - вид збоку; б - вид зверху.

Після зйомки достатньої кількості серій загального плану, які дозволяють захопити геометрію об'єкта, необхідно додатково крупним планом зняти всі значущі деталі, щоб вони правильно відобразилися на готовій моделі. Для отримання найкращих результатів об'єкт має бути освітлений рівномірно, без жорстких тіней чи відблисків. При польових зйомках найкращий результат можна отримати під час зйомок у похмуру погоду, оскільки саме при таких умовах освітлення дозволяе досягти бажаної відсутності тіней і відблисків. 
Отримані знімки завантажуються в спеціальне програмне забезпечення для виконання орієнтування та обробки зображень. При цьому здійснюється ідентифікація та вимірювання координат контрольних марок, ідентифікація та вимірювання зв'язуючих точок об'єкта; обчислення початкових значень невідомих величин внутрішнього, зовнішнього та взаємного орієнтування а також координати точок об'єкта та їх апроксимація; урівнювання невідомих величин внутрішнього, зовнішнього та взаємного орієнтування; визначення та видалення великих похибок, що виникають при вимірюванні точок зображення.

На основі отриманої хмари точок об'єкта здійснюється побудова каркасної та текстурованої моделей для подальшої цифрової обробки та аналізу.

Результати дослідження. Застосування технології та методики обробки отриманих цифрових знімків здійснено в програмному забезпеченні в Agisoft Metashape 1.76 на прикладі фотознімання пам'ятника роботи скульптора Галини Кальченко - погруддя Лесі Українки, що встановлено перед корпусом «В» Волинського національного університету ім. Лесі Українки на вул. Винниченка, 30 в Луцьку у 1986 році на честь 115-ї річниці від дня народження письменниці.

Знімання об’єкту було здійснено камерою сматрфону Samsung Galaxy S9 (SM-G960F) з наступними параметрами: роздільна здатність 12 MPix; розмір сенсора 1/2.55"; розмір пікселя $1.4 \mu \mathrm{m}$; поле огляду $77^{\circ}$; подвійна діафрагма 1.5/2.4. Для даної камери було здійснено калібрування в програмному забезпеченні Agisoft Metashape 1.76. В результаті отримано наступні параметри камери (табл. 1), графіки дисторсії (рис. 3) та похибок (рис. 4).

Таблиця 1

Параметри камери смартфону Samsung Galaxy S9 (SM-G960F)

\begin{tabular}{|l|l|}
\hline Фокальна відстань, пікселів: & 31592,3912 \\
\hline Координати головної точки зображення: & $-21,0176 ;-12,622$ \\
\hline Коефіцієнт радіальної дисторсії: & 0,0144127 \\
\hline Коефіцієнти тангенціальної дисторії: & $-0,0010052 ; 0,000845348$ \\
\hline
\end{tabular}




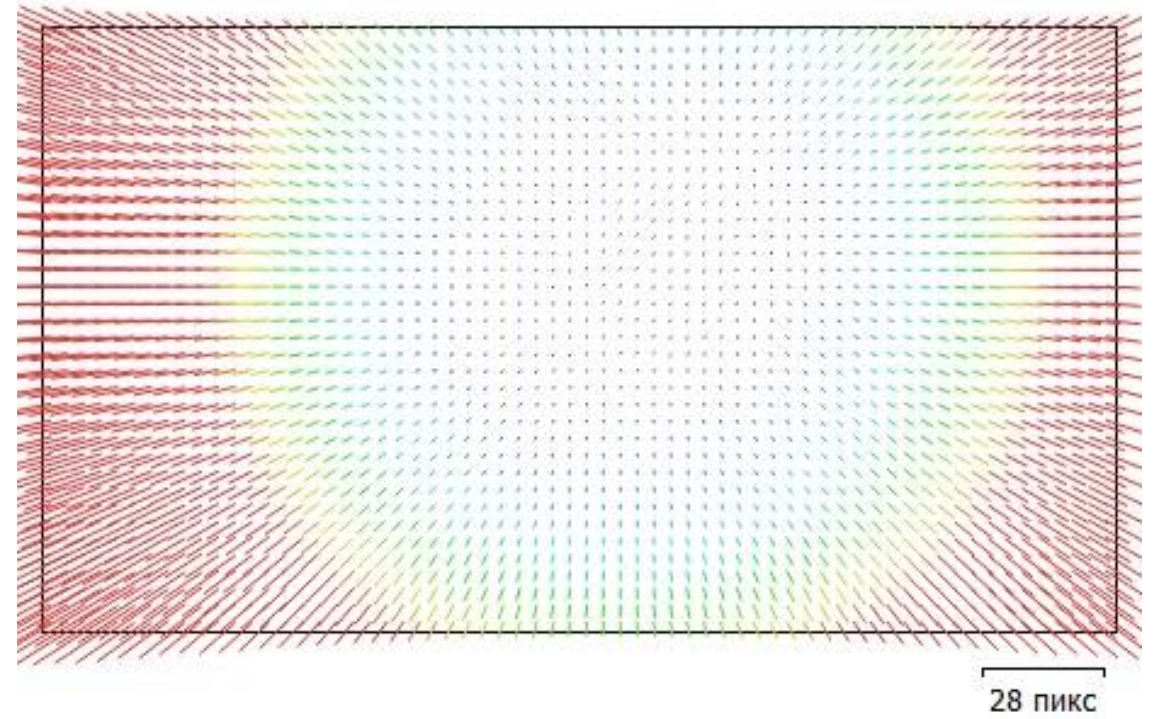

Рис. 3. Графік дисторсії зображення камери

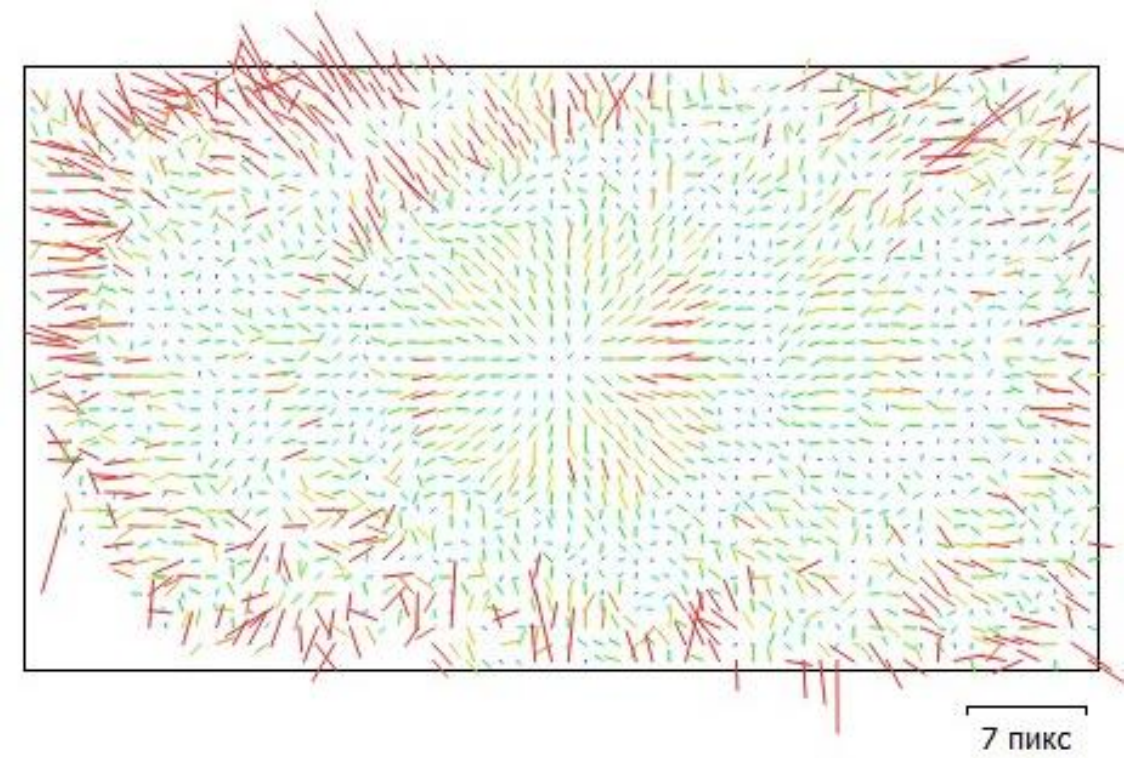

Рис. 4. Графік похибок зображення камери

В результаті знімання отримано 77 зображень об'єкта. Приклади окремих зображень наведено на рис. 5. 


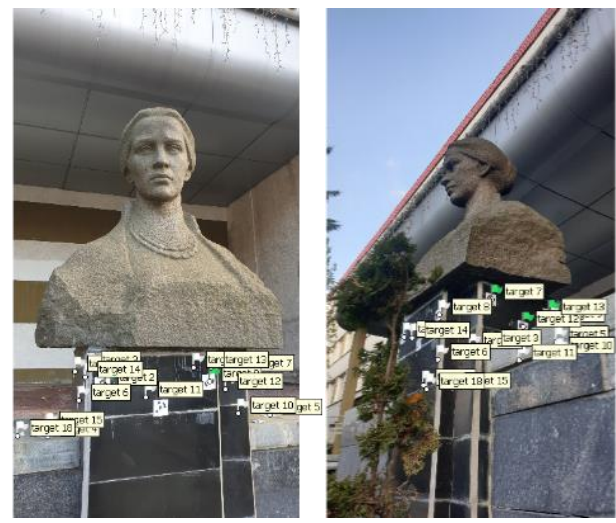

Рис 5. Окремі зображення погруддя Лесі Українки

В результаті застосування операторів виділення точок інтересу для кожного знімку формуєтсья неструкторований список точок зображення (ix координати та значення показника інтересу) в програмному забезпеченні Agisoft Metashape. Подальший аналіз цих точок дозволяє виділити однорідні властивості об'єкта та видалити невідповідні елементи зображень.

Співставлення точок на основі двох областей зображення може здійснюватись у наступних випадках:

- одночасне співставлення точки на декількох зображеннях;

- одночасне співставлення множини точок на множині зображень;

- долучення до розгляду геометричних умов в просторі зображень та просторі об'єкту;

- включення до розгляду цілісності моделі об'єкта.

Достовірність визначеності окремих точок об’єкту представлена на рис. 6

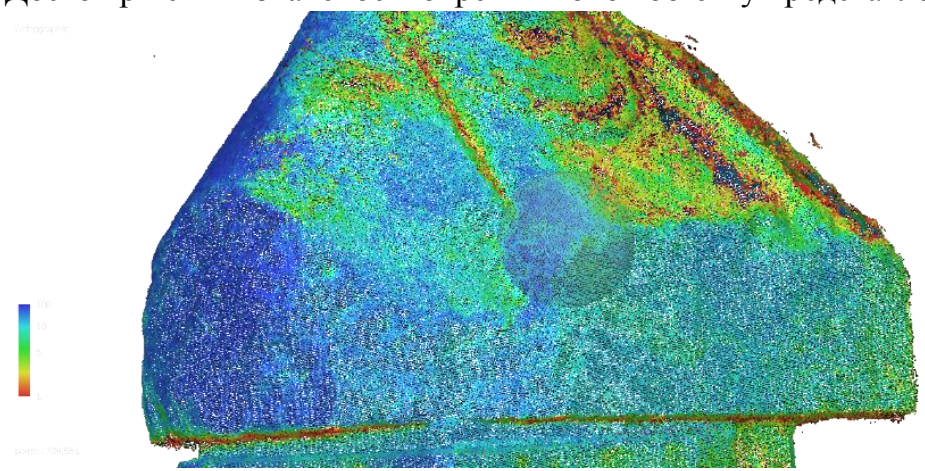

Рис.6 Фрагмент визначення достовірності точок 
Наступним етапом обробки є побудова каркасної моделі об'єкта на основі щільної хмари точок, що отримані фотограмметричним методом на основі множини стереопар знімків. При побудові каркасної моделі на границі об'єкту можуть спостерігатись «артефакти» неіснуючих об'єктів, які необхідно в напівавтоматичному режимі вилучити.

На основі щільної хмари точок будується тривимірна тріангуляційна модель, що складається із множини полігонів (трикутників). Фрагмент полігонів представлено на рис. 7.

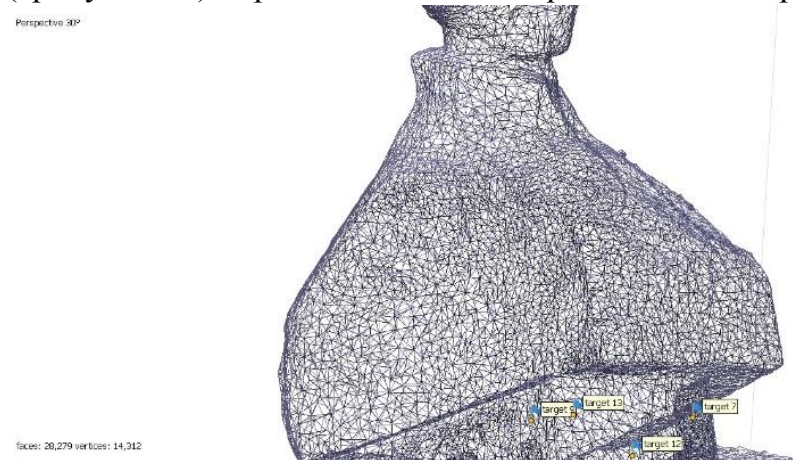

Рис. 7. Фрагмент тріангуляційної моделі об'єкту

На основі тривимірної тріангуляційної каркасної моделі та стереопар зображення на завершальному етапі формується реалістична текстурна модель об'єкту, що представлена на рис. 7.

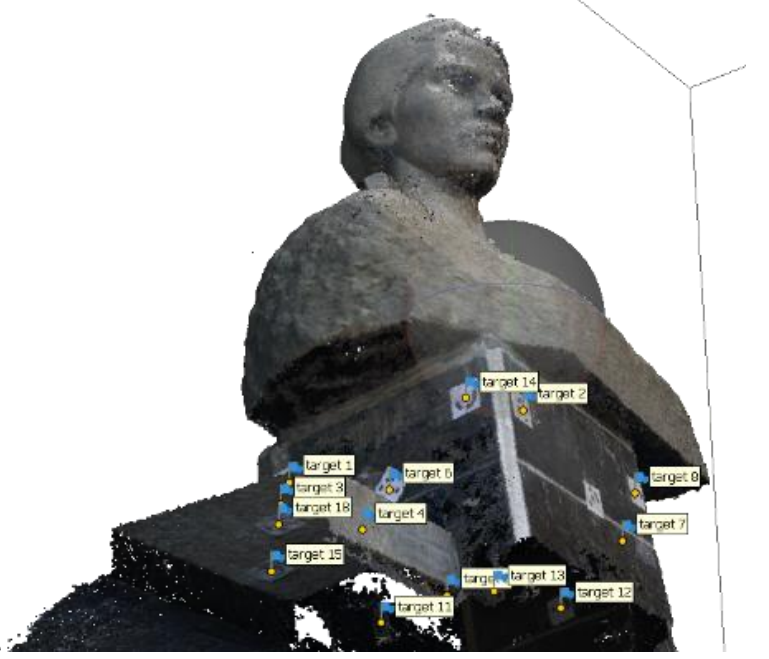

Рис. 7. Текстурна модель погруддя Лесі Українки 
Подальший аналіз тривимірної моделі можна здійснювати якісно і кількісно. Для якісної оцінки можливо згенерувати цифрові зображення моделі у просторі під різними кутами або тривимірні зображення у різноманітних форматах вузькоспеціалізованого програмного забезпечення. Для кількісної оцінки каркасну модель об'єкту можливо експортувати в САПР та ГІС з подальшим статистичним та просторовим аналізом моделі.

Висновки. Підсумовуючи короткий виклад проблеми розвитку та впровадження фотограмметрії в архітектурі, містобудуванні та збереженні культурної спадщини зазначимо, що необхідним процесом є збір даних дистанційними методами та фотограмметрична обробка знімків. Незважаючи на те, що сучасні методи фотограмметрії дозволяють вирішувати більшість завдань, в тому числі із застосуванням широко розповсюджених бюджетних камер, iii впровадження в реальне виробництво залишається мізерним.

Результати фотограмметричної тривимірної реконструкції об'єктів можуть слугувати основою для подальшої обробки в САПР та ВІМ, значно заощадивши час на попередні дослідження.

\section{References}

1. Boochs, F. Lowcost image based system for nontechnical experts in cultural heritage documentation and analysis./ F. Boochs, G. Heinz, U. Huxhagen,H. Müller, // International Archives of the Photogrammetry, Remote Sensing and Spatial Information Sciences. 2007 pp. $165-170$

2. Remondino, F. Reality-based 3D documentation of natural and cultural heritage sites - techniques, problems, and examples. / F. Remondino, A. Rizzi, // Applied Geomatics, 2(3), 2010, pp.85-100.

3. Reu, J.D. Towards a three-dimensional costeffective registration of the archaeological heritage. / J.D. Reu, G. Plets, G. Verhoeven, P.D. Smedt, M. Bats, B. Cherretté, W.D. Maeyer, J. Deconynck, D. Herremans, P. Laloo// Journal of Archaeological Science, 40(2), 2013, pp.1108-1121.

4. Dhonju, H. K. Feasibility Study of Low-cost Image-Based Heritage Documentation in Nepal/ H. K. Dhonju, W. Xiao, V. Sarhosis, J. P. Mills, S. Wilkinson, Z. Wang, L. Thapa, U. S. Panday, // Int. Arch. Photogramm. Remote Sens. Spatial Inf. Sci., vol. XLII-2/W3, 2017, pp. 237- 242.

5. Gonizzi Barsanti, S., Remondino, F. and Visintini, D. 3D Surveying and Modelling of Archaeological Sites /S. Gonizzi Barsanti, F. Remondino, D. Visintini // ISPRS Ann. Photogramm. Remote Sens. Spatial Inf.Sci., II-5/W1, 2013, pp. 145-150

6. Dorozhynskyi O.L. Analitychna ta tsyfrova fotohrammetriia: navch. posib. dlia stud. vuziv. Lviv: vydavnytstvo NU Lvivska politekhnika, 2002. $164 \mathrm{~s}$. 
7. Hnera V.A. Zastosuvannia aerofotohrammetrychnykh metodiv dystantsiinoho zonduvannia zemnoi poverkhni v arkheolohii. 2012. K. Pratsi Tsentru pamiatkoznavsta, vyp. 21. S. 76-91.

8. Synhatulyn R.A. Fotohrammetrycheskye tekhnolohyy v arkheolohyy (kratkyi ystorycheskyi ocherk) // Ystorycheskye, fylosofskye, polytycheskye y yurydycheskye nauky, kulturolohyia y yskusstvovedenye. Voprosы teoryy y praktyky. Tambov : Hramota, 2013. \#3. C. 148-152.

\section{Список використаної літератури}

1. Boochs, F. Lowcost image based system for nontechnical experts in cultural heritage documentation and analysis./ F. Boochs, G. Heinz, U. Huxhagen,H. Müller, // International Archives of the Photogrammetry, Remote Sensing and Spatial Information Sciences. 2007 pp. 165-170

2. Remondino, F. Reality-based 3D documentation of natural and cultural heritage sites - techniques, problems, and examples. / F. Remondino, A. Rizzi, // Applied Geomatics, 2(3), 2010, pp.85-100.

3. Reu, J.D. Towards a three-dimensional costeffective registration of the archaeological heritage. / J.D. Reu, G. Plets, G. Verhoeven, P.D. Smedt, M. Bats, B. Cherretté, W.D. Maeyer, J. Deconynck, D. Herremans, P. Laloo// Journal of Archaeological Science, 40(2), 2013, pp.1108-1121.

4. Dhonju, H. K. Feasibility Study of Low-cost Image-Based Heritage Documentation in Nepal/ H. K. Dhonju, W. Xiao, V. Sarhosis, J. P. Mills, S. Wilkinson, Z. Wang, L. Thapa, U. S. Panday, // Int. Arch. Photogramm. Remote Sens. Spatial Inf. Sci., vol. XLII-2/W3, 2017, pp. 237- 242.

5. Gonizzi Barsanti, S., Remondino, F. and Visintini, D. 3D Surveying and Modelling of Archaeological Sites /S. Gonizzi Barsanti, F. Remondino, D. Visintini // ISPRS Ann. Photogramm. Remote Sens. Spatial Inf.Sci., II-5/W1, 2013, pp. 145-150

6. Дорожинський О.Л. Аналітична та цифрова фотограмметрія: навч. посіб. для студ. вузів. Львів: видавництво НУ Львівська політехніка, 2002.164 с.

7. Гнера В.А. Застосування аерофотограмметричних методів дистанційного зондування земної поверхні в археології. 2012. К. Праці Центру пам'яткознавста, вип. 21. С. 76-91.

8. Сингатулин Р.А. Фотограмметрические технологии в археологии (краткий исторический очерк) // Исторические, философские, политические и юридические науки, культурология и искусствоведение. Вопросы теории и практики. Тамбов : Грамота, 2013. №3. С. 148-152. 